\title{
Collaboration in Virtual Environments Honouring the Métis Method of Visiting
}

Fiona P. McDonald

University of British Columbia, Okanagan

Hanna M. Paul

University of British Columbia, Okanagan

\begin{abstract}
During COVID-I9, many collaborative research teams and community partners pivoted to undertake their work in a virtual way. In this discussion, we capture the mechanics, logic, and situations under which virtual methods became relevant to applied interdisciplinary work. Using a shared voice, we chart the nuances of training and research through the redesign, the reimagining of research protocols, and the nuanced cultural gaps that exist between virtual connection and in-person visiting with community partners, Métis Knowledge Keepers, and experts. Through referencing our reflexive archive of experiences, emails, fieldnotes, and meeting minutes, we address how our attempt to simulate virtual informed consent has consequently provided insights into the value of co-creation and the importance of honouring visiting as a Métis method in virtual environments.
\end{abstract}

Keywords: Métis methods; care; collaboration; virtual methods; informed consent

Résumé: Pendant la pandémie de COVID-I9, de nombreuses équipes de recherche collaborative et de partenaires communautaires se sont orientés vers le travail virtuel. Dans cet article, nous appréhendons les mécanismes, les logiques et les situations par lesquelles les méthodes virtuelles ont gagné en pertinence pour le travail interdisciplinaire appliqué. Nous retraçons d'une voix commune les nuances de la formation et de la recherche à travers le réexamen et la reconception des protocoles de recherche ainsi que les écarts culturels subtils qui existent entre, d'une part, les connexions virtuelles et, d'autre part, les visites en personne chez les partenaires communautaires, les gardiens du savoir métis et les experts. Puisant dans nos archives réflexives 
d'expériences, de courriels, de notes de terrain et de comptes rendus de réunions, nous expliquons comment nos efforts de simulation d'un consentement éclairé virtuel ont mis en lumière la valeur de la co-création et l'importance d'honorer la visite en tant que méthode métis en milieu virtuel.

Mots-clés: méthodes métis; care; collaboration; méthodes virtuelles; consentement éclairé

\section{Introduction}

Trom designing projects and preparing grant applications to undertaking

fieldwork, collaborative ethnography is a generative process that supports applied outcomes by creating new spaces for diversity, respect, and innovation. This collaborative process is even more relevant during a global health crisis. Yet even in a pandemic, one of the many joys that comes with collaborative research and training is the reciprocal relationship that is central to mentorship. Mentorship is a two-way street lined with care, patience, and compassion. In this reflection, we discuss an original community-based research project that took place during the pandemic on unceded Syilx territory in the Okanagan. Through our discussion, we touch upon what collaboration looks like between student and supervisor and more specifically, between a Métis student and a non-Indigenous supervisor.

We initially designed the project in the early days of January 2020, imagining we would use a range of qualitative methods (interviews, focus groups, surveys, archival work, and participant observation) that draw from anthropological, community-based research, and Indigenous research paradigms. Hanna M. Paul's positionality as a Métis scholar was pivotal to determining the project's questions, and Fiona P. McDonald's training as an anthropologist was instrumental to the methodological design for this community-based research project. This reflection is, at its core, our autoethnography about our pivot to imagining and actualizing these methods in a virtual environment. It maps out the "aha!" moment of multimodal research when the role of visiting as a Métis methodology manifested in sync with the ethnographic (Collins and Durington 2020). The concept of Métis visiting is addressed at length by Indigenous scholar Chantal Fiola (Red River Métis Anishinaabe) in Rekindling the Sacred Fire: Métis Ancestry and Anishinaabe Spirituality (2015). Fiola explains that Métis knowledge transmission is rooted in visiting, kitchen parties, and storytelling, which help 
ensure future generations have the tools to survive holistically. For our project, we needed to find a way to honour Métis cultural understanding of visiting as a method when moving our research into virtual environments. While our objective in the research was to focus on what happens when Métis methods and ethnographic fieldwork are adapted to virtual contexts through what is ultimately the practice of networked anthropology (Collins and Durington 2020), we started by first asking ourselves: How can Métis methods be adapted to virtual fieldwork without losing the vitality, connection, and intimacy that is at the core of kitchen parties and visiting in the community?

\section{Creating a Shared Voice}

The shared voice you will read in this autoethnographic piece is considered, balanced, and crafted. The process of finding our shared voice has been emergent and negotiated, and it was exciting to find it together as we did fieldwork in real-time over Zoom, wrote together in Google Docs, and respected each other's unique expertise and lived experiences. Our approach to supervision and learning was interactive and iterative-we both participated in research design, data collection, and analysis. We found our shared voice iteratively. We are using this voice to address how we can collaboratively innovate virtual ethnographic fieldwork (or more accurately, networked anthropology) in the context of a pandemic and in a way that centres care, creativity, and consent.

Collaboration is an important aspect of our work because, as we created this autoethnographic reflection, we co-imagined its outline and together determined its threads, reflected on shared fieldwork experience in a pandemic (through our notes), and articulated what we both felt are the main insights for readers. While the possibility of a power imbalance could exist between Hanna, as a student, and Fiona, as a supervisor, we managed this potentiality through open dialogue and ensuring our shared voice respects each of our contributions. We each took the lead on various elements and then rewrote and edited this article together, line by line. While some may feel our language is informal, it is a formal element of collaborative work emerging in anthropology today. Take, for example, recent publications such as Anthropologist as Curator (2020), edited by anthropologist Roger Sansi, and Collaborative Anthropology Today: A Collection of Exceptions edited by anthropologists Dominic Boyer and George E. Marcus (202I), in which the contributing authors embrace an anecdotal tone as an approach to theorizing collaboration and experimentation. We also draw upon Fiona's long-standing experience with research collaboration and her 
work on ethics, creativity, and mixed-methods (Cantarella, McDonald, and Murphy 20I7; McDonald, Cantarella, and Murphy 20I7; Murphy, McDonald, and Cantarella 2017).

With that, our reflexivity takes us back to when our collaboration began.

\section{Where the Project Began}

In early January 2020, we began preparing an application for the Irving K. Barber Undergraduate Research Award at the University of British Columbia, Okanagan (UBCO) - a four-month, funded research project for students to undertake with a faculty member in the summer between their third and fourth years.' It was Hanna's intention to connect her training in anthropology and Indigenous studies with Indigenous feminist theory to look actively, reflexively, and locally at Métis Moon Time (menstruation) teachings and learn what elements of that knowledge are sharable-meaning, what was not sacred or community-protected knowledge. This qualitative project aimed to unpack the complexities of varied cultural perceptions surrounding Moon Time (menstruation) and how this relates to girls' and young women's body images. At the recommendation of another of Hanna's mentors, Fiona's colleague, and leading Métis scholar, Dr. Gabrielle Legault, we reached out to the Central Okanagan Elizabeth Fry Society (COEFS) to see how a community-based research project with team members from COEFS might unfold. COEFS was established in 1972 in the Central Okanagan of British Columbia and "has evolved as an open network of activists, advocates, and volunteers working together to bring about social change for women [and] children. [Their] mission is to bring about an end to violence, eliminate poverty and seek justice for women [and] children here in our community" (Central Okanagan Elizabeth Fry Society n.d.). Simply put, their mission is to create equality, inclusiveness, integrity, respect, and accountability in our communities.

Collaboratively with COEFS, we planned to focus on their Girls United program to understand possible connections between Moon Time (menstruation) teachings and young women's body images. ${ }^{2}$ The logic for this was driven by the fact that there was little culturally relevant information on menstruation for participants, and the program was seeking insights on a teaching module that would help facilitators connect with local First Nations and Métis experts to support this teaching. To do this, we had to begin by evaluating the COEFS's Girls United program. We aimed to evaluate the overall program, make recommendations for both programming and curriculum modifications, and design a 
new module around Moon Time (menstruation) (Paul and McDonald 202I). Girls United is a program for empowerment and cohort-building among girls aged twelve to seventeen. It is run by the COEFS through schools in the Okanagan. A program facilitator meets with the girls weekly for ten weeks to deliver a curriculum that addresses a variety of topics from online safety to healthy relationships. There are also safe spaces in the program to engage the young women in discussions arising from their questions, concerns, and lived realities. It is designed as an empowerment program and cohort building effort. Absent from this program, however, is a clear focus on culturally relevant knowledge around menstruation teachings. As an emerging Métis scholar, Hanna wanted to learn more about what Métis knowledge is sharable that could inform this program. With these insights, the plan was to prepare a new curriculum module for the program as an applied outcome of the summer research project.

As a young Métis woman, Hanna was in a unique position to undertake this research project. Being an Indigenous, cisgender woman has brought challenges that some people may never experience; this part of Hanna's intersectional identity would be foundational to unpacking the lived realities of menstrual and Moon Time teachings. In this way, each element of Hanna's identity and training informed the project design and is why Métis methods were central to this project from the very start. Fiona's experiences as a non-Indigenous, cisgender woman and trained anthropologist allowed her to connect with Hanna not just academically but through lived realities of menstruation and her own culturally relevant history with taboos around menstruation.

\section{A Bit More Background}

The genesis of this project is framed within the legacy of colonisation, of which residential schools are a particularly poignant reality (Rutherdale 2003; Tatz 2005; Wilk, Maltby, and Cooke 2017). In this context of residential schools, young Indigenous girls and women were enculturated into western medical ideologies around sanitation and hygiene as related to menstruation. Such ideologies differ from Indigenous conceptions of Moon Time (menstruation), which is considered a special and sacred time for women (Gaudet and CaronBourbonnais 2015). Over time, Indigenous girls and women were exposed to colonial narratives rooted in a patriarchal logic (Martin 200I), which inevitably influenced their perspectives on the menstrual cycle. Through assimilationist

policies across Canada, Indigenous girls and women were forced to adopt and internalize demoralizing and alienating beliefs about their bodies (Kelm I998). 
After we gathered this background research as the first step in the preparation of this ethnography, we then needed to gain new insights through interviews with Métis Knowledge Keepers and Girls United participants, supporters, and facilitators. The project was set to produce rich contextual knowledge and resources for and with our community partner. We had the best-laid plans for a collaborative summer research project in the Okanagan with COEFS. Funding was in place, and, on 6 March 2020, we met with our community partner to work through timelines, discuss how we would do the fieldwork together, and consider potential outcomes. From there, Hanna was all set to have a desk in the Institute of Community Engaged Research at the University of British Columbia, Okanagan (UBCO) for the summer months while Fiona's research lab was being designed and readied for a construction tender. We identified potential folks to interview and were dreaming in "technicolour" about the possibility of using knowledge gained from this project to develop a smartphone app for Girls United program participants. ${ }^{3}$

Then I6 March 2020 happened. Under the guidance of the Provincial Health Officer of British Columbia, Dr. Bonnie Henry, the pandemic locked down the Okanagan. UBCO campus closed and all research involving human subjects was curtailed. The future became virtual and our collaboration became digitally networked. We thought, "What now?" We waited for four weeks until the dean's office gave us the green light to continue with the project (and four weeks under stay-in-place orders felt like twenty-four weeks pre-COVID-I9). On I7 April, we received word that we could make a case to continue our research, but only if it could be done virtually. In this pivot, as our methods changed and our project scope was reimagined, a space for reflection opened, allowing us to think through the pragmatics of virtual, collaborative, community-based qualitative research that provides safety and care in the time of COVID-I9.

\section{Pivoting and Pragmatics}

When the pandemic locked down the Okanagan, we met with our community partner on Zoom. We discussed and revised the logistics of what we could do as we waited for UBCO Research Ethics Board approval for our adapted virtual methods. We were aware that stress levels were increasing around the world as economic realities meant either the loss of work or furloughed positions, homeschooling, a lack of access to technology and stable internet connections, separation from loved ones, loss of friends and families to the virus, and other daily stressors. British Columbia's stay-in-place orders were active, and with that 
came increased stresses for many COEFS clients. Overnight, the workload of staff and support workers doubled, if not quadrupled, with women, youth, and families needing more support, safety, and care. Furthermore, school closures meant the 2020 Girls United program was curtailed. As such, there would be no interactions (surveys, participant observations, or interviews) with the Girls United participants as we had planned. Instead, we decided to rely on evaluations by past participants accessed through the Girls United archive and other qualitative ways of knowing.

We learned in real-time about the dramatic spike in gender-based violence and domestic abuse being reported under the pandemic locally and nationally in both the media and social media feeds. These reports are reflected in the number of calls coming into agencies and services across the countryorganizations that are already operating on shoestring budgets (Anderson 2020; Bogart 2020; Patel 2020). The media reports referenced the findings of a Statistics Canada survey, Impacts of COVID-I9, which was completed by 4,600 people across Canada between29 March and 3 April 2020. It is important to note, however, that this survey was only distributed to ten provinces and no territories; therefore, it is not a full reflection of national realities.

The executive summary of the Statistics Canada survey draws attention to domestic violence statistics, noting that " $8 \%$ of Canadians reported that they were very or extremely concerned about the possibility of violence in the home. This percentage was higher for women (Io percent) than men (6 percent)" (Statistics Canada 2020). This statistic is echoed in the findings and recommendations of a 25 June 2020 report from Amnesty International titled Canada: Submission to the UN Special Rapporteur on Violence Against Women on COVID-I9 and the Increase of Domestic Violence Against Women (Amnesty International 2020). Public health professor Patricia O'Campo from the University of Toronto's Dalla Lana School of Public Health was also responding to this news by modifying the smartphone app WithWomen Pathways, which she had been designing for women at risk of partner or spousal violence (Anderson 2020). It was around this same time, in mid-April, that we began to see the reality of the increased pressures, demands, and work on our community partner.

We realized, based on these reports of increased stress, overwork, and vulnerability, that we needed to have care and compassion when considering how our community-university partnership contributed to the well-being of our community. Care is inherent in trust and relationship building and is essential 
to research partnerships. We reviewed goals, addressed timelines and bandwidth, and made sure everyone felt heard and supported. We also ensured that the project still met the short- and long-term goals of the COEFS.

At this same time, serendipitously, we (Fiona and Hanna) both found ourselves working remotely in Alberta. Suddenly we were on $\triangleleft \Gamma^{n} b \cdot \dot{\Gamma} \dot{\gamma}^{n} b b^{n} \Delta b^{2}$ (Amiskwacîwâskahikan) Treaty Six territory on the opposite side of Edmonton's hinterlands, working virtually with partners and participants on unceded Syilx territory in Kelowna. When conducting virtual research, considering where we work from matters. We approached our virtual settings through the lens of ethics and respect, which are central to Métis methods and at the core of doing no harm in anthropological research. As such, land acknowledgements grounded us in time and space. The virtual does not absolve us of the ethics and responsibility of acknowledging where we work (University of British Columbia 2020). Since the virtual exists across territories, we are reminded of our connections with all of humanity and our responsibility to honour the commitments of the Truth and Reconciliation Commission of Canada (2015). As we found with this project, the need to decolonize positionality does not stop when we do research in virtual environments. Rather, it creates greater connections between participants in distributed virtual territories (âpihtawikosisân 2016).

While working remotely and in a distributed (or networked) way, we had a clear plan for virtual engagement. With no participants for us to engage with in-person because schools had closed and gone online, we moved forward with our research with a heavier emphasis on evaluating the Girls United program. Hanna expanded the comprehensive literature review. Then it came time to prepare a research ethics application. While Research Ethics Boards (REB) at Canadian universities are not always organized to understand the logic of social science research, let alone Indigenous research, we are more convinced than ever that the REB application is one of the best training grounds for co-creating the logistics of a project, finding a shared voice in a project, and meeting new ideas born out of circumstance. Here the circumstance was the pandemic and the need to create a virtual ethnographic method that engaged with Métis methods (Center for Global Ethnography 2020; Miller 2020; Mozilla 2020; Penna 2020).

We approached the redesign intending to create safe, inclusive meetings that were a gesture toward a face-to-face meeting — something akin to virtual visiting (Baudrillard 1994). By prioritizing safety, we situated our care for each 
other as collaborators and for the participants who were asked to meet us in Zoom to talk about Moon Time (menstruation). With a new lens, we began by considering how digital tools could become the intermediary and participant in the informed consent process.

\section{Virtual Methods Unfold}

It was in this digital divide that visiting as a Métis method became centrally important when we thought through how to collect informed consent. No longer able to sit across the table from collaborators and do a page-by-page review of the scope of the project, the benefits of participation, and the process of anonymity, we were faced with finding a new way to obtain informed consent securely and efficiently. One afternoon in late May, as we were on Zoom together screen-sharing and doing a deep dive into the REB portal as part of the training process, we reached the stage of how to refine the informed consent process. Starting with the basics, we thought perhaps we could email the informed consent form as a PDF and have the individual sign the form and email it back to us. Surely facilitating this critical step through our secure institutional email was logical; this could not be the first time that researchers needed a participant to return a signed informed consent form electronically. But we hesitated, thinking about making things efficient for folks already burdened with too much time online. After further reflection, we reconsidered the email option for two reasons. First, we did not want to create extra stress, and second, we realized we were making a dangerous assumption about people's access to printers, scanners, or the software for creating e-signatures. Granted, we were aware that participants were being asked to have access to a smartphone, tablet, or computer to meet us on Zoom. The irony of reflecting on this is not lost on us now!

It was then that we had our technological realization. This moment met us in the middle of numerous emails from UBC IT Services advising research community members that new Zoom protocols were in place as they shifted to Canadian servers to become research compliant during COVID-I9. Ultimately, we also needed to be research compliant. This led us to think about using Qualtrics in the same way you would for an online survey. The responsive interface of Qualtrics, a nimble online survey software tool, would let us set up the informed consent document and virtually turn the page via Zoom. We embedded a link in the Zoom chat box for the interviewee to click on. To virtually turn the page, they had to actively click the radio button to indicate understanding and agreement. This allowed participants a performative space to manually 
sign their informed consent form and allowed us to secure and record consent via Zoom in real-time. This process-in-action was, ironically, rather enjoyable. Participants used phones and computers to move through the form. The Qualtrics interface also allowed participants to download their signed informed consent form as well as the additional wellbeing resource document for support networks in the Okanagan. This process allowed us to obtain informed consent, verify the signature, and start the interview within minutes, as we would have done in person.

We were fortunate that the informed consent process was not new to many of the participants, and they expressed a degree of empathy that was unexpected but welcomed at this critical step. It felt as though we were using technology to overcome technology and participants' understanding helped us craft a shared space where the edges of our monitors could dissolve. We wanted this experience to be as real as being face-to-face and visiting. In this case, by keeping in mind the deeply complex Métis method of visiting and building relations, the simulation of turning pages helped us to turn a semi-structured interview into a moment of connection.

\section{Visiting Virtually in a Global Pandemic and the Ramifications of Zoom Fatigue}

You do not have to listen too hard to hear the rumblings about Zoom fatigue in the breakout rooms of large-scale meetings or across social media. It is real. We have even let it slip in at the margins of this reflection. As we cowrite this piece, we are on Zoom and in Google Docs with our phones next to us, gobbling up data. But at the same time, we are innovating what collective writing looks like in a pandemic. We are also accepting that the fatigue is not about the Zoom software, rather it is about the realities of being physically apart but digitally switched on.

Yet through this exhaustion, we find connection with each other and with experts whose willingness to talk about topics too often left at the margins of society creates a sense of companionship. We created a safe, virtual space to discuss the lived realities of Moon Time, menstruation, cycles, and periods, rather than visiting around the kitchen table. Overall, while the purpose of the interviews was two-fold, to learn about Métis knowledge related to Moon Time (menstruation) that is shareable, by ensuring we created a virtual environment with care, we learned about histories, about a variety of smartphone apps that one can use to track our own menstrual needs, and about our shared experiences 
as women. Our gendered experience in this project is a central connection that should not be downplayed. While these may come across as rather meta observations to those outside of this work, we want to note that in our efforts to create a safe environment for the interviewees beyond informed consent, we found ourselves talking about the safety of online environments during virtual interviews. Following up on this, one Métis Knowledge Keeper shared with us: "Thank you so much for your mindful presentation of the interview experience and questions."

Through all of this, we have continued to build our relationship and mentorship as collaborators. We are sharing lived experiences as cisgender women who have coped with menstruation without teachings and who have created body images without formal mentoring or support. Over several months, we shared our reflections on our lived experiences and on the literature, coming together in the virtual, semi-structured interviews to bring our respective cultural perspectives into dialogue with our community partner, their allies, and Métis Knowledge Keepers. In this effort, despite our fatigue with Zoom meetings, the reality of virtual visiting made more visceral the importance of unpacking and engaging deeply with Métis methods.

Through the process of this virtual research, it became apparent that visiting must be recognized as a key Métis method that is established over time. Visiting is a method of multilayered relation-building that creates intimacy between those who are participating. The bond created through visiting and storytelling is built and nurtured over time, bringing to mind the familiar adage that we need to share "one hundred cups of tea" as we build connection and trust. It is not a short process. This is not something that can be fully simulated in a virtual interview or visit-but it is still something that connects us with the community. Métis methodologies and methods such as visiting are inherently care-centric and, as such, visiting came up organically in this project because caring and compassion are needed more than ever during a pandemic. But, because Métis methods are meant to uphold natural laws, which are rooted in Wahkômâtowin (kinship), ${ }^{4}$ virtual visiting cannot fully capture the kinship and "intergenerational cultural transmission" (Fiola 2015, II9) that is usually conducted through common, physical space-holding. However, our experience interviewing and visiting with Métis Knowledge Keepers within the virtual space allowed us to reflect upon the importance of kinship and visiting when interviews are conducted in person. Our collaborators reflected on the critical 
importance of holding physical space for crucial conversations and relationship building, and of sharing space in-person, for the Girls United participants and the transmission of knowledge. This reinforces the importance of building trust and community within the Girls United program and the value of Métis visiting as a method in collaborative research (Kovach 2009). We learned, particularly, that the Girls United program participants bonded with one another and the program's group facilitator only near the end of the program. This demonstrates the crucial nature of kinship in these physical spaces. While the need to extend the program in person is real, the reality may be that its reach only lands in a virtual world.

Métis methodology also tells us that there is a relationship between the researcher and the research being done, that the research itself also has a spirit (Wilson 2008). Kinship is not limited to the bonds between humans but extends to the bonds with all beings, including living research (Fiola 2015; Wilson 2008). For this reason, creating space for the researchers to be introspective about their projects and findings is another vital Métis method that we have come to see clearly through writing this reflection.

\section{Virtual Spaces and the Future}

While we live in this virtual limbo to stay safe and keep those around us and in our communities safe, we are faced with the reality that Gen Zers, Millennials (Hanna), and Gen Xers (Fiona) are all striving for social connection through tools meant to connect us when we research at a distance. Although we resolved how to obtain virtual informed consent and maintain a safe environment for our collaborators and ourselves, we were faced with thinking through how researching in virtual spaces both determines and limits our efforts to bring Métis and anthropological methods fully into dialogue.

We do not know when we can safely return to turning the pages of the informed consent documents in person with interviewees and community partners or attend kitchen parties and engage in visiting. But in the meantime, when we think about the methods being reshaped through the pandemic and the digital tools and technologies available to us for collaborative, communitybased research, we recognize that we must continue to collaborate and create networked space for care, compassion, and inclusion in our work. In this, we are not advocating for the Indigitalization ${ }^{5}$ of methods in the virtual world. That misses the point completely. What we are advocating for is what inherently gets 
missed in virtual approaches to research: the deeply embodied work of Métis methods and care in collaborative research.

Fiona P. McDonald, University of British Columbia, Okanagan, fiona.mcdonald@ubc.ca

Hanna M. Paul,

University of British Columbia, Okanagan, hannapi8@student.ubc.ca

\section{Acknowledgments}

We wish to thank the Central Okanagan Elizabeth Fry Society for their amazing resilience and collaboration with us and the community during

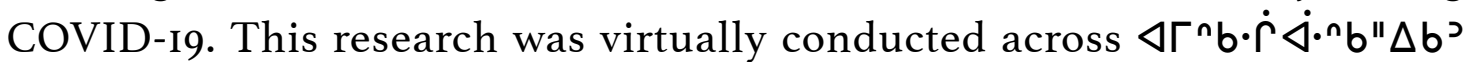
(Amiskwacîwâskahikan) on Treaty Six territory (Alberta) and unceded Syilx ancestral territory (British Columbia). Funding was provided by the University of British Columbia, Okanagan (UBCO) Irving K. Barber Faculty of Arts and Sciences. We are grateful for the generous comments received through the peer review process and by the editors that have strengthened our work. And we thank Jon Corbett for advising us on correct use of Plains Cree syllabics fonts for this article.

\section{Notes}

- This project was supported through the Collaborative + Experimental Ethnography $\mathrm{Lab}\left(\mathrm{CE}^{2} \mathrm{Lab}\right)$, co-directed by Fiona P. McDonald, and funded by the Canadian Foundation for Innovation and the British Columbia Knowledge Development Fund.

2 Our sincere thanks to Michelle Novakowski, former Executive Director of COEFS, who worked steadfastly to make this project happen and lay the groundwork for it to continue on into the future.

3 Creating a smartphone app for girls and young women in the Girls United program is a desired next step by COEFS. Part of our ongoing community collaboration with COEFS is aimed at securing funding for the app, which will allow past and present Girls United participants to access curriculum content, support, and resources. The app would target past, present, and future Girls United participant needs for extending community building in real-time in digital environments and connecting young women resources in real-time. 
4 We are aware of the various spellings of this Cree and Métis concept and acknowledge that spelling is specific to the dialect and culture they belong to. This original Cree word embodies the Cree natural laws. We also acknowledge that there is a constant underlying concept of connection and kinship regardless of spelling (Macdougall 2006; Northern Michif Dictionary n.d.). For our discussion, we are using the Northern dialect and spelling common to Northern Alberta where Hanna's community connections are rooted in Buttertown.

5 We are attempting to coin a new word here that in no way is to be conflated with the incredible work of Gerry Lawson and others at the University of British Columbia, Vancouver and the Museum of Anthropology who work on "Indigitization" (see https://www.indigitization.ca).

\section{References}

Amnesty International. 2020. "Canada: Submission to the UN Special Rapporteur on Violence Against Women on COVID-I9 and the Increase of Domestic Violence against Women." Amnesty International. https://www.amnesty.org/en/documents/ amr20/2606/2020/en (accessed 26 August 2020).

Anderson, Scott. 2020. "COVID-I9: U of T Researchers Seek to Protect Women from Abuse with Re-Tooled Safety App." University of Toronto News, 26 May. https://www. utoronto.ca/news/app-built-u-t-researchers-re-tooled-protect-women-domesticviolence-during-covid-19 (accessed 26 August 2020).

âpihtawikosisân. 20I6. "Beyond Territorial Acknowledgments." Âpihtawikosisân: Law, Language, Culture, 23 September. https://apihtawikosisan.com/2016/o9/ beyond-territorial-acknowledgments (accessed I5 November 2020).

Baudrillard, Jean. 1994. Simulacra and Simulation. Translated by Sheila Faria Glaser. Ann Arbor: University of Michigan Press.

Bogart, Nicole. 2020. "Advocates Scramble to Help Domestic Abuse Victims as Calls Skyrocket during COVID-I9." CTV News, 5 May. https://www.ctvnews.ca/health/ coronavirus/advocates-scramble-to-help-domestic-abuse-victims-as-callsskyrocket-during-covid-I9-I.4923IO9 (accessed 20 August 2020).

Boyer, Dominic, and George E. Marcus, eds. 202I. Collaborative Anthropology Today: A Collection of Exceptions. Ithaca, NY: Cornell University Press.

Cantarella, Luke, Fiona P. McDonald, and Keith M. Murphy. 20I7. "Evaluation,” Cultural Anthropology, 27 July. https://web.archive.org/web/20181213224947/https://culanth. org/fieldsights/II79-evaluation (accessed I5 November 2020). 
Center for Global Ethnography. 2020. "Sarah Pink Interview - Doing Ethnography Remotely.” 25 May. YouTube video, 26:37. https:/www.youtube.com/watch?time_ continue $=22 \mathrm{I} \& \mathrm{~V}=\mathrm{z} \_\mathrm{t} 7 \mathrm{WkQ2c} 4 \&$ feature $=\mathrm{emb}$ logo (accessed 25 May 2020).

Central Okanagan Elizabeth Fry Society. n.d. "Our Impact." Central Okanagan Elizabeth Fry Society. -https://empowerific.com/about-efry (accessed I5 November 2020).

Collins, Samuel Gerald, and Durington, Matthew Slover. 2020. "The Case for Letting Anthropology Be Quarantined: COVID and the End of Ethnographic Presence.” entanglements 3 (2): 92-96.

Fiola, Chantal. 20I5. Rekindling the Sacred Fire: Métis Ancestry and Anishinaabe Spirituality. Winnipeg: University of Manitoba Press.

Gaudet, Janice Cindy, and Diane Caron-Bourbonnais. 20I5. "It's in Our Blood: Indigenous Women's Knowledge as a Critical Path to Women's Well-Being." AlterNative: An International Journal of Indigenous Peoples II (2): I64-I76. https://doi. org/IO.II77/II77I80II50IIOO206.

Kelm, Mary-Ellen. 1999. Colonizing Bodies: Aboriginal Health and Healing in British Columbia 1900-1950. Vancouver: University of British Columbia Press.

Kovach, Margaret. 2009. Indigenous Methodologies: Characteristics, Conversations, and Contexts. Toronto: University of Toronto Press.

Macdougall, B. 2006. "Wahkootowin: Family and Cultural Identity in Northwestern Saskatchewan Metis." The Canadian Historical Review 87 (3): 43I-462.

Martin, Emily. 200I. The Woman in the Body: A Cultural Analysis of Reproduction. Boston: Beacon Press.

McDonald, Fiona P., Luke Cantarella, and Keith M. Murphy. 20I7. "Responsibility." Cultural Anthropology, 27 July. https://web.archive.org/web/20181213224944/https:// culanth.org/fieldsights/II78-responsibility (accessed I5 November 2020).

Miller, Daniel. 2020. "How to Conduct an Ethnography during Social Isolation." 3 May. YouTube video, 20:13. https://www.youtube.com/watch?v=NSiTrYB-oso\& feature $=$ emb_logo (accessed 3 May 2020).

Mozilla. 2020. "ET Speaker Series: Ghost Work in Pandemic Times with Mary Gray, Microsoft Research.” 30 April. YouTube video, I:I7:06. https://www.youtube.com/ watch?v=aw3pKIYbQ5M (accessed 22 August 2020).

Murphy, Keith M., Fiona P. McDonald, and Luke Cantarella. 20I7. "Collective Hunchwork." Cultural Anthropology, 27 July. https://web.archive.org/web/ 20181213224942/https://culanth.org/fieldsights/II77-collective-hunchwork (accessed I5 November 2020). 
"Northern Michif Dictionary." n.d. http://www.metismuseum.ca/northern_michif_ dictionary.php (accessed I5 February 202I).

Patel, Raisa. 2020. "Minister says COVID-I9 is Empowering Domestic Violence Abusers as Rates Rise in Parts of Canada." CBC News, 27 April. https://www.cbc.ca/news/ politics/domestic-violence-rates-rising-due-to-covidI9-I.554585I (accessed 25 August 2020).

Paul, Hanna, and Fiona P. McDonald. 202I. The Girls United Program Evaluation: Métis Moon Time Teachings and Young Women's Body Images. Collaborative \& Experimental Ethnography Lab Community Report Series. Kelowna, BC: ICER Press.

Penna, Stacy. 2020. "Webinar Recap: COVID-I9 and Virtual Qualitative Fieldwork." Nvivo, 8 April. https://www.qsrinternational.com/nvivo-qualitative-data-analysissoftware/resources/blog/covidi9-webinar-recap (accessed I5 August 2020).

Rutherdale, Myra. 2003. Women and the White Man's God: Gender and Race in the Canadian Mission Field. Vancouver: University of British Columbia Press.

Sansi, Roger, ed. 2021. Anthropologist as Curator. London: Bloomsbury Press.

Statistics Canada. 2020. "Canadian Perspectives Survey Series I: Impacts of COVID-I9." Statistics Canada, 8 April. https://wwwi5o.statcan.gc.ca/nI/daily-quotidien/200408/ dq200408c-eng.htm (accessed 25 August 2020).

Tatz, Colin Martin. 2005. Aboriginal Suicide Is Different: A Portrait of Life and SelfDestruction. 2nd edition. Canberra: Aboriginal Studies Press.

Truth and Reconciliation Commission of Canada. 2015. Truth and Reconciliation Commission of Canada: Calls to Action. Winnipeg, Manitoba: Truth and Reconciliation Commission of Canada. http://trc.ca/assets/pdf/Calls_to_Action_ English2.pdf (accessed 15 November 2020).

University of British Columbia. 2020. "Doing Land Acknowledgements." University of British Columbia Library, 5 November 5. https://guides.library.ubc.ca/distanceresearch-xwi7xwa/landacknowledgements (accessed I5 November 2020).

Wilk, Poitr, Alana Maltby, and Martin Cooke. 20I7. "Residential Schools and the Effects on Indigenous Health and Well-Being in Canada: A Scoping Review." Public Health Reviews 38 (I): I-23.

Wilson, Shawn. 2008. Research Is Ceremony: Indigenous Research Methods. Halifax, NS: Fernwood Pub. 